\title{
¿Por qué (a veces) las teorías de la prueba nos parecen inútiles?*
}

\section{Why (Sometimes) do the Theories of Proof Seem Useless to us?}

\author{
Rodrigo Coloma Correa \\ Doctor en Derecho \\ Profesor Titular de Derecho, Universidad Alberto Hurtado \\ rcoloma@uahurtado.cl
}

\section{Resumen}

Este texto trata de las dificultades que deben sortear algunas teorías de la prueba, para constituirse en una perspectiva útil desde la cual los litigantes y jueces que participan en los procesos judiciales asuman — de manera articulada - los desafíos de la gestión probatoria y de la decisión de los hechos. El foco del análisis da cuenta, principalmente, del problemático compromiso con la verdad por correspondencia sostenido por las teorías cognoscitivistas, las que en las últimas décadas han concentrado parte importante de la producción académica. Para ilustrar las anunciadas dificultades se analiza el impacto la relevancia del error, falsedad, falsificación e insuficiencia probatoria en el contexto de la acción de revisión, y en una de las causales del recurso de nulidad penal.

Palabras claves: Derecho probatorio, adaptación y progreso, teorías jurídicas, acción de revisión.

\begin{abstract}
This article adresses the difficulties that some theories of proof must overcome to become a useful perspective from which both litigants and judges could approach the challenges posed by the proof and decisions about facts. This article reveals the problematic commitment of cognitive theories to the correspondence theories of truth, which over the last decades have dominated an important part of the scholarly production. To illustrate the aformentioned difficulties, I analyze the relevance of the impact of error, falsity, falsification and insufficient evidence within the context of the wrongful conviction claim and on one of the key grounds for appealing the criminal conviction in Chile.
\end{abstract}

Keywords: evidence law, adaptation and progress, legal theories, wrongful conviction claim.

\footnotetext{
* Este trabajo presenta resultados del proyecto financiado por el Fondo Nacional de Desarrollo Científico y Tecnológico, FONDECYT 1170872 "Prueba de los hechos. Coordinación entre el lenguaje de la teoría y el lenguaje de la práctica". Agradezco los valiosos comentarios de Daniela Accatino, Claudio Agüero, Beatriz Arriagada y José Manuel Fernández a distintos borradores de este trabajo.
} 
"La palabra «teoría» procede del griego theoria que viene de la misma raíz que «teatro», una palabra que significa «ver»o «hacer un espectáculo». Luego, podemos muy bien decir que una teoría es, en primer lugar, una manera de formarse una idea, es decir, una manera de mirar el mundo, y no una forma de conocimiento de lo que es el mundo".

David Bohm. La totalidad y el orden implicado.

\section{De los usos esperables de las teorías que tratan de problemas de prueba y de sus diferencias con las teorías sobre interpretación de disposiciones normativas}

Las actividades propias de la gestión y solución de problemas probatorios resultan, a lo menos, tan relevantes ${ }^{1}$ como las que tratan asuntos interpretativos. Pese a ello, hay diferencias considerables en la manera en que tanto los abogados litigantes ${ }^{2}$ como los jueces acometen dichas tareas. Así, en lo que concierne a lo probatorio se reconoce un alto protagonismo a la imaginación (y aquello, en principio, no incomoda pues se asume como señal de sagacidad y no, de improvisación); en cambio, en el espacio de lo interpretativo los discursos resultan relativamente predecibles ${ }^{3}$ (y aquello tampoco molesta pues se entiende equivaler a sabiduría y no, a rigidez en el pensamiento). El asunto no deja de ser curioso, pues los problemas de prueba no son tan diferentes a los de interpretación. ${ }^{4}$

Los abogados y jueces disponemos de teorías para hacer frente a los asuntos interpretativos. ${ }^{5}$ A pesar de contar con niveles de adhesión variable, las teorías contribuyen a estandarizar los discursos potenciales. Así, los usuarios de las teorías pueden desentenderse de todo aquello que forma parte de lo que es por todos sabido, ${ }^{6}$ concentrando, en cambio, sus esfuerzos en lo

\footnotetext{
${ }^{1}$ Respecto de la decisión que será tomada existe, prima facie, igual carga de fundamentación. Dependerá del caso concreto a qué se le deberá prestar mayor o menor atención.

${ }^{2}$ En adelante, me referiré a ellos, indistintamente, como abogados o litigantes.

${ }^{3}$ En el momento interpretativo, por cierto, hay mucho de imaginación, pero el discurso respectivo vela porque permanezca oculta. Sobre aquello se ha escrito bastante. Ver, entre otros: CHIASSONI (2011), pp. 56 y ss.; NINO (1991), pp. 321-338.

${ }^{4}$ COLOMA (2019), p. 429.

${ }^{5}$ En rigor, las prácticas interpretativas no suponen de los sujetos el dominio de cierta teoría. En tal sentido, basta llamar la atención en la circunstancia que cualquier persona puede interpretar una cierta formulación normativa, sin haberse sometido previamente a un proceso formativo. Más aún, el resultado no tendría por qué ser de baja calidad si el intérprete es agudo. Sin embargo, a diferencia de quien sí domina una teoría, el amateur se verá en dificultades para justificar el nuevo texto que propone. A ello se suma que, no sería de extrañar, que el nivel de sofisticación y de rapidez para hacerlo no resulte equiparable al de quien opera desde una teoría.

${ }^{6}$ En condiciones de normalidad, aquello que forma parte de lo teóricamente asentado no requiere ser explicitado, más aún, hacerlo deja entrever cierta sospecha respecto a los saberes del auditorio al que uno se dirige. La explicitación en condiciones de normalidad (como opuesto a crisis) solo pareciera tener sentido, si lo
} 


\section{Polít. Crim. Vol. 15, No 30 (Diciembre 2020), Art. 4, pp. 614-638 [http://politcrim.com/wp-content/uploads/2020/10/Vol15N30A4.pdf]}

que la teoría — hasta ese momento — ha dejado abierto a la participación. ${ }^{7}$ En otras palabras, el uso de la teoría implica una descarga argumentativa consistente en no tener que enfrentarse a una serie de implícitos, ${ }^{8}$ salvo en las raras ocasiones en que la teoría misma sea desafiada. ${ }^{9}$ A su vez, si los abogados o los jueces no dominan cabalmente (o no adhieren), por ejemplo, a la(s) teoría(s) del delito, del acto (o negocio) jurídico o de los derechos fundamentales (por nombrar solo algunas), el auditorio de especialistas al cual traten de persuadir no se encontrará demasiado llano a acoger lo planteado, incluso si la propuesta concreta no estuviere exenta de agudeza. ${ }^{10}$

La palabra teoría es una palabra compleja y sus posibilidades/significados dependen de sus contextos de uso. En el ámbito que aquí interesa, se espera que las teorías nos ayuden a ordenar un cúmulo de actividades mentales y discursivas mediante las cuales se requiere conectar insumos tan variados, como pueden serlo disposiciones normativas, valores (como la justicia o la seguridad), relatos de testigos e intereses de las partes en un litigio. ${ }^{11}$ En el mundo de los juristas — aparte de las teorías asentadas en la dogmática - el vocablo teoría evoca construcciones lingüísticas tan diversas como podrían serlo la (muy abstracta) teoría pura del derecho cuyo foco se dirige, entre otras cosas, a los problemas de la validez de las disposiciones jurídicas o a la separación entre el derecho y la moral; hasta las (muy concretas) teorías del caso cuyo foco apunta a la protección y organización de los intereses específicos de las partes en un juicio.

Las teorías son puntos de partida del trabajo jurídico y no puntos de llegada, pues sus usuarios no tienen un rol pasivo, sino que participan en la construcción de nuevos productos disciplinarios (solución de enigmas). ${ }^{12}$ Así las cosas, salvo el caso de los aprendices o de los miembros noveles de la comunidad disciplinaria que requieren internalizar una forma de trabajo estándar, las teorías no debieran ser entendidas como productos estáticos. La teoría, de esa manera, pasa a ser un componente clave para llegar lo suficientemente lejos. ${ }^{13}$ Esto

que se pretende hacer es meta-teoría. El asunto se relaciona — en palabras de Kuhn — con la tensión esencial entre la tradición e innovación. La primera que representa la normalidad contribuye a hacerse cargo de las cuestiones de detalle, o si se quiere mirar con mayor profundidad; la segunda, en cambio, favorece que se asuman perspectivas más amplias y abiertas a desafiar lo ya asentado. Para más, ver KUHN (1993), pp. 248262.

${ }^{7}$ El concepto de participación es complejo e interesante. Mediante él se reconoce que el sujeto participante imprimirá una determinada forma al resultado. SKOLIMOWSKY (2016), p. 90, pp. 212-240.

${ }^{8}$ ECO (1996), p. 11. Ver también, ALEXY (1989), pp. 256 y ss.

${ }^{9}$ El foco del desafío puede apuntar hacia distintas direcciones. Parafraseando a Lakatos, podrá atacarse el centro (del programa de investigación) o su cinturón protector, es decir, el conjunto de las hipótesis auxiliares que mantienen protegido lo más relevante. LAKATOS (1983), p. 230.

${ }^{10}$ En rigor, hablar de un solo auditorio es algo confuso. La división del trabajo dentro de la comunidad disciplinaria lleva a que algunos estén mucho más preocupados de resolver asuntos usando el derecho y otros a la determinación de lo que es el derecho. La clase de auditorio en la que aquí pongo atención es fundamentalmente el primero. Por cierto, la existencia de ambos tipos de participantes es importante para la conservación (¿Y progreso?) del campo de trabajo. Ver TWINING (1997), pp. 64-65.

${ }^{11}$ Las conexiones en la práctica distan de ser transparentes, ver PERELMAN (1988), p. 210. Es labor de una meta-teoría desentrañar cómo se lleva a cabo en la cotidianeidad, a partir de una tarea reconstructiva.

${ }^{12}$ MORIN et al. (2003), p. 25.

${ }^{13}$ Las teorías conservan un nivel de abstracción suficiente como para que las actividades asociadas no resulten puramente mecánicas. En otras palabras, la teoría no exime de la imaginación, pero sí proporciona un trasfondo que evita partir desde demasiado atrás. 


\section{Polít. Crim. Vol. 15, No 30 (Diciembre 2020), Art. 4, pp. 614-638 [http://politcrim.com/wp-content/uploads/2020/10/Vol15N30A4.pdf]}

no obsta a que si la acumulación de saberes alcanza un elevado nivel de consistencia y, a la vez, resulta lo suficientemente abarcadora —en términos de cubrir un dominio específico del campo de trabajo - liberará a los abogados y jueces de la carga de tener que pensar en asuntos de detalle. Cuando esto sucede se pasa al nivel de las doctrinas, cuya utilización hace posible la automatización de tareas argumentativas más de detalle, es decir, se pre-figura una secuencia que facilita el tránsito desde un punto A (lo no problematizado) hacia un punto B (lo problematizado). ${ }^{14}$

Las teorías sobre la prueba de los hechos se presentan de una manera mucho más escurridiza que las que operan en el ámbito interpretativo. ${ }^{15}$ Esta falta de articulación conduce a una fragmentación asistemática de los problemas ${ }^{16} \mathrm{y}$, en consecuencia, se hace muy difícil identificar la posición desde la cual hablan los jueces y abogados al momento de formular sus sentencias y alegatos, respectivamente. ${ }^{17}$ En otras palabras, las (proto) teorías desde las cuales se opera en los asuntos probatorios diseccionan el objeto de estudio en términos que las distintas actividades ejecutadas cuentan, ya sea, con límites relativamente precisos donde operar; o bien, posibilitan un espacio amplísimo de discrecionalidad dentro del cual el adjudicador deberá lidiar con la incertidumbre. Lo más sorprendente de esa manera de desenvolverse es que no facilita la comunicación fluida entre los distintos participantes ${ }^{18}$ comprometidos con la generación de una decisión que aspira a ser reconocida como debidamente justificada. Me explico, si en un caso concreto la actividad se encuentra fuertemente marcada por los límites respecto a lo que debe hacerse y hay poco espacio para la discrecionalidad, se estará ejecutando algo muy diferente a otro caso en que la discrecionalidad es amplia y los límites escasos. En el primer caso, habrá escasa participación de los agentes en el producto que se construye; en el segundo habrá mucha. Una teoría útil debiera hacerse cargo de estas diferencias, prestando especial atención a la importante dimensión constitutiva del proceso probatorio.

Para ilustrar lo precedente, vale la pena llamar la atención que en el ámbito de lo probatorio disponemos de algunos conceptos que delimitan, estrictamente, ciertas actividades, como es el caso de la admisibilidad de determinados medios de prueba. ${ }^{19}$ De manera consistente con ello, las discusiones en esta clase de asuntos suelen ser bastante previsibles. Sin embargo, la regla general está representada por lo que ocurre en otros espacios mucho menos colonizados,

\footnotetext{
${ }^{14}$ Probablemente esta es una de las circunstancias que explican que la memorización se resista a abandonar la enseñanza y la práctica de la abogacía (es más económico repetir una secuencia que estar repensándola cada vez).

${ }^{15}$ Con el espacio interpretativo aludo a problemas que regularmente asume la dogmática y no a cuestiones metainterpretativas.

${ }^{16}$ Una de las particularidades que suele reconocerse a lo teórico es su carácter sistemático. WILLIAMS (2011), P. 66.

${ }^{17}$ David Bohm reconoce la necesidad de dividir las cosas hasta un punto en que se tornen manejables, pues en caso contrario nos estancaríamos. El problema - advierte - es que se puede ir más allá de lo que funciona. En sus palabras: "Guiado por un concepto fragmentario de su propio mundo, el hombre intenta romperse a sí mismo y su mundo, para que así todo parezca corresponder a su modo de pensar”. BOHM (2018), pp. 20-21.

${ }_{18}$ COLOMA y AGÜERO (2014), pp. 393-396.

${ }^{19}$ A este nivel, los discursos suelen ser estereotipados. Por cierto, aquello no es obstáculo a que la valoración de las soluciones a las que se arribe susciten discrepancias. Se podrán criticar los fundamentos teóricos (o las disposiciones normativas), pero aquello no obsta a que sea fácil alcanzar niveles elevados de consenso respecto a si una solución en concreto es o no consistente con lo que se plantea desde la teoría.
} 


\section{Polít. Crim. Vol. 15, No 30 (Diciembre 2020), Art. 4, pp. 614-638 [http://politcrim.com/wp-content/uploads/2020/10/Vol15N30A4.pdf]}

en que tanto la variedad como la profundidad de los argumentos resultan difícilmente reducibles a regularidades. Más aún, la carencia de teorías asentadas estimula desacuerdos aparentes (disenso en el uso de las palabras) y de la mano de ello, a la desviación de los problemas que realmente interesan. ${ }^{20}$ En otras palabras, carecemos de un punto de partida común apto desde el cual se lleven a cabo tareas probatoriamente relevantes. ${ }^{21}$ Esta especie de vacío metodológico conduce a pensar que, en la mayoría de los asuntos de prueba, más que el dominio de un conjunto de saberes (o una técnica) lo que realmente importa es el arte de decir $\operatorname{cosas}^{22}$ de una manera funcional a la aceptación de las pretensiones de quienes están compitiendo por sus derechos y deberes en los juicios. Por cierto, este estado de cosas es riesgoso si se trata de conservar la hegemonía de un campo de trabajo, pues hay que demostrar que se está en mejores condiciones que un recién llegado, para arribar a una solución argumentativamente satisfactoria. ${ }^{23}$

El espacio del razonamiento probatorio es un buen ejemplo de lo recién expresado. En los tiempos que corren, distintos sistemas jurídicos han ido forjando expectativas respecto de lo que puede ser logrado mediante la valoración conforme a la sana crítica o, si se prefiere, valoración racional de la prueba. El problema en torno a ello es que, si se presta atención en nuestras prácticas argumentativas, estamos lejos de haber alcanzado un nivel de sofisticación apropiado en la construcción de relaciones entre, por una parte, las conjeturas a probar o refutar $^{24}$ en un proceso judicial y, por la otra, las pruebas generadas en las audiencias respectivas. ${ }^{25}$ Desde cierta perspectiva, lo que se busca mediante la actividad probatoria es la construcción de una forma narrativa que posibilite un tránsito comunicativo desde los medios de pruebas hacia las conjeturas (y viceversa). ${ }^{26}$ Entre los juristas, sin embargo, no resulta para nada claro lo que se encontraría implicado en el aludido tránsito, en términos de tornar legítima una determinada forma discursiva. ${ }^{27}$ Desde otra perspectiva, se entendería que los aludidos medios de prueba pueden ser reconstruidos como efectos (o, en términos más débiles, señales) provocados por los acontecimientos aludidos en las conjeturas a demostrar. En este último caso, la relación de causalidad presupuesta podría ser vinculada a probabilidad, plausibilidad u otra forma de conexión por el estilo. El asunto no termina allí: la prohibición de non liquet (dejar la decisión pendiente mientras no haya suficiente claridad) ha llamado la atención de muchos juristas respecto del papel que cabría asignar a los estándares de prueba. Así, de una manera progresiva, hablar de estándares de prueba se ha

\footnotetext{
${ }^{20}$ KAHNEMAN (2012), pp. 132-135.

${ }^{21}$ Según lo indicado por Bohm en el epígrafe de este texto, careceríamos de una teoría.

${ }^{22}$ TWINING (1987), pp. 89 y ss.

${ }^{23}$ La división del trabajo supone que quienes se desempeñan en un área son capaces de producir mejores resultados y en menor tiempo que quienes no pertenecen a ella.

${ }^{24}$ Hablo de refutación, a pesar que podría no ser del todo correcto el uso de esta expresión. En rigor, hay muchos procesos judiciales en que basta dificultar la obtención del estatus de demostrada/probada respecto de cierta conjetura. En tales casos, no sería del todo correcto indicar que ha habido una refutación, dado que la conjetura podría quedar en pie, pero no en términos de forzar una decisión de condena o de aceptación de una demanda.

${ }^{25}$ No es evidente que estemos situados en una mejor posición que aquella alcanzada recurriendo a la prueba tasada o a la íntima convicción.

${ }^{26}$ Entre otros, BERNS (1999), pp. 39, 195; PENNINGTON y HASTIE (2004), pp. 192-221.

${ }^{27}$ Con esto no se desconocen avances, sino se llama la atención que las teorías que se han ido dibujando en esta línea se han visto enfrentadas a serias dificultades si se pretende que sean usadas sostenidamente en los procesos judiciales. Una visión crítica acerca de las posibilidades de esta clase de proyectos puede verse en TARUFFO (2007), pp. $231-270$.
} 


\section{Polít. Crim. Vol. 15, No 30 (Diciembre 2020), Art. 4, pp. 614-638 [http://politcrim.com/wp-content/uploads/2020/10/Vol15N30A4.pdf]}

ido tornando indispensable en un mundo de incertidumbres,${ }^{28}$ pero no sabemos qué hacer con ellos. $^{29}$

La tendencia a aislar categorías incómodas ha incidido en que no se logre construir teorías suficientemente complejas que se hagan cargo de las relaciones entre pruebas y conjeturas. ${ }^{30}$ Aquello constituye un factor que contribuye a perpetuar la existencia de dos formas de razonar entre los abogados: una de ellas (interpretativa) se exhibe como sofisticada y, en ocasiones, suficientemente articulada como para no poner en tela de juicio la competencia de los abogados y jueces para gestionarla y controlarla; ${ }^{31}$ la otra (probatoria), en cambio, se muestra como intuitiva y no resulta en absoluto evidente que litigantes y jueces sean los sujetos más competentes para hacerse cargo de ella. ${ }^{32}$

\section{2. ¿Qué explica que las teorías de la prueba no susciten alta adhesión en litigantes y jueces, ni tampoco en las escuelas de Derecho?}

Desde hace algún tiempo, en Iberoamérica se advierte un esfuerzo importante por llenar espacios discursivos que atañen a lo probatorio y que se encuentran incómodamente abiertos para el imaginario de los juristas. ${ }^{33}$ No es de extrañar, entonces, que para hacer frente a esta especie de descontrol se lleven a cabo importantes esfuerzos para instalar una teoría de la prueba que capture la atención de jueces y litigantes, y sea reconocida como teoría dominante. Hasta el momento, el éxito ha sido solo parcial. Por una parte, se encuentra disponible una literatura que, sin ser especialmente abundante, supera con creces a la que resultaba accesible hasta hace algunas décadas y, lo más interesante, los nuevos textos han logrado atraer a un número creciente de lectores. ${ }^{34}$ Por la otra, las prácticas de los abogados y de los jueces — más allá de conceder alguna cita ocasional a estos nuevos textos — no han cambiado de una manera suficiente el razonamiento probatorio como para que se pueda afirmar que la teoría las está re-configurando. En otras palabras, las teorías no logran que quienes participan en los procesos judiciales piensen desde ellas.

\footnotetext{
${ }^{28}$ BAYÓN (2008), pp. 15-34, plantea que si mediante el estándar de prueba no se logra la distribución de errores conforme a criterios objetivables, las fuertes expectativas epistémicas presentes en modelos como los de Bentham deben ser repensadas.

${ }^{29}$ COLOMA (2016), pp. 23-57; GONZÁLEZ LAGIER (2020) pp. 87-97.

30 Un ejemplo interesante lo constituye la distinción de Larry Laudan entre distintos valores que serían perseguidos en los juicios o sistemas judiciales penales. Se trata de valores extra-epistémicos, valores propiamente epistémicos y valores quasi-epistémicos (problemas de distribución de errores). La fragmentación de Laudan - que, en su caso, puede explicarse ya que él asume un punto de vista que podríamos llamar de un observador externo - es recogida en muchos textos, pues facilita bastante el estudio de los problemas probatorios, aun cuando afecta considerablemente las posibilidades de analizar la actividad probatoria como un continuum. LAUDAN (2005), pp. 96-97.

31 Curiosamente, los espacios más estandarizados se encuentran, en principio, más expuestos al uso de inteligencia artificial y, de esa manera, los jueces y abogados corren un mayor riesgo de ser reemplazados por máquinas a un mediano plazo.

${ }^{32}$ Más allá de la dimensión política que subyace a ella, el magnetismo que pudiera ejercer un sistema de jurados legos pasa por una cierta frustración respecto de las conexiones entre pruebas y conjeturas que los abogados y jueces están en condiciones de realizar.

${ }_{33}$ Respecto del imaginario de los jueces en asuntos de valoración de la prueba, ver COLOMA y AGÜERO (2014), pp. 377 y ss.

${ }^{34}$ Ver AGÜERO (2016), pp. 89-102.
} 


\section{Polít. Crim. Vol. 15, № 30 (Diciembre 2020), Art. 4, pp. 614-638 [http://politcrim.com/wp-content/uploads/2020/10/Vol15N30A4.pdf]}

En lo que sigue me propongo explorar: ¿Por qué teorías de la prueba —que cuentan con una innegable calidad narrativa y hacen gala de no poca erudición- están siendo incapaces de permear en los jueces, en los litigantes y en las escuelas de derecho ${ }^{35}$ ? El foco de atención estará puesto en las llamadas "teorías racionalistas de la prueba", ${ }^{36}$ también conocidas como teorías cognoscitivistas de los hechos. Ellas impregnan trabajos —más o menos abarcadores- de autores como Michele Taruffo, Marina Gascón, Jordi Ferrer, Daniel González, Perfecto Andrés o Luigi Ferrajoli. ${ }^{37}$ La razón de la elección es de lo más sencilla: aunque no es la única propuesta disponible, es la que ha puesto mayor empeño en formar una comunidad alineada bajo algunas ideas comunes que aspiran alcanzar una posición hegemónica.

Para no irse con rodeos, el problema que ha conspirado en contra del éxito de las propuestas de estos autores radica en la circunstancia de que no han tenido suficientemente en cuenta las particularidades que afectan al objeto de sus investigaciones: ¿Qué es lo que realmente se trata de lograr a través de actividades probatorias como lo son la gestión de pruebas y la decisión de hechos? y ¿Cuánto de ello resulta posible y razonable obtener? El asunto es complejo y difícilmente reducible - al menos en los tiempos que corren - a las categorías ofrecidas por una teoría monista. ${ }^{38}$ Las teorías cognoscitivistas no dan mucha cabida a los matices, sino más bien se han dejado hechizar por los avances alcanzados en las ciencias naturales, en razón de sus sorprendentes tecnologías. El problema es que, más allá de algunas concesiones difíciles de no asumir ${ }^{39}$ sus planteamientos solo se encuentran en condiciones

\footnotetext{
${ }^{35}$ Ver COLOMA et al. (2019), pp. 129-152.

${ }^{36} \mathrm{La}$ etiqueta teoría/tradición racionalista de la prueba ha sido estudiada con bastante profundidad por William Twining en el contexto del derecho anglosajón. TWINING (1994), pp. 32-91. Una reconstrucción más comprimida de tales ideas se encuentra en ANDERSON et al. (2015), pp. 115-120. Desde hace algún tiempo, dicha locución también aparece con frecuencia en textos en español, haciéndose los ajustes contextuales: ACCATINO (2020), pp. 85-102; AGUILERA (2016), pp. 163-189. Entre nosotros, varios autores se autoreconocen como partícipes de esta tradición: ver, por ejemplo, VALENZUELA (2017), p. 13. Uno de los problemas de su denominación es que cuenta con una carga emotiva excesiva al colocar (implícitamente) a quienes no comparten sus presupuestos en una posición de irracionalismo. Esto complica las cosas, pues enfrentar los presupuestos de quienes están situados en una posición dominante no tiene per se nada de irracional. Para más, ver ARNAU (2017), p. 20.

${ }^{37}$ En el ámbito nacional, los autores señalados son influyentes. Varios de ellos han visitado repetidamente nuestro país y sus ideas son frecuentemente citadas favorablemente en los artículos académicos. Un mapa general puede verse en COLOMA (2016), pp. 48-51.

${ }^{38}$ Este asunto no será abordado en lo que sigue pues excedería de los propósitos de este trabajo. Basta, en todo caso, las siguientes dos observaciones: a) Cuando se aplica un estándar más exigente versus cuando se aplica un estándar menos exigente, el producto obtenido no es el mismo. No me refiero con ello a que la decisión probatoria podría diferir - asunto que aparece de una obviedad irritante - sino que aquello que es calificado como un hecho bajo un estándar de prueba exigente no aspira a significar lo mismo que aquello que es llamado hecho en un contexto escasamente exigente; y b) En asuntos en los que se abordan problemas de Derechos Humanos el valor asignado al relato en sí difiere al que se le atribuye en problemas que no alcanzan dicho estatus. En el primero, al relato puede reconocérsele un valor intrínseco (la sola circunstancia de poder formularlo es valioso), cuestión que no ocurre en el segundo. TODOROV (2013), p. 48.

${ }^{39}$ Por una parte, estas teorías prestan atención a las restricciones a la admisibilidad como impedimentos para la toma de buenas decisiones. Especialmente relevantes son, en este sentido, los aportes de Larry Laudan, que han sido traducidos a la lengua española. Por otra parte, hay una preocupación respecto de los estándares de prueba, en cuanto a mecanismos de distribución de errores en situaciones de incertidumbre. En ocasiones, el reconocimiento de los límites de los sistemas probatorios, lleva a pensar que estaríamos enfrentándonos a un pseudo problema y, en consecuencia, el descuerdo sería más aparente que genuino. En ese orden de cosas se
} 


\section{Polít. Crim. Vol. 15, No 30 (Diciembre 2020), Art. 4, pp. 614-638 [http://politcrim.com/wp-content/uploads/2020/10/Vol15N30A4.pdf]}

de hacerse cargo seriamente de un número muy reducido de los casos que ingresan al sistema judicial. ${ }^{40}$

Las teorías cognoscitivistas de los hechos - una denominación más descriptiva que el de teorías racionalistas de la prueba- se encuentran radicalmente comprometidas con un concepto de hechos dependiente de una idea (concepción) de verdad bastante fuerte, como lo es el de verdad como correspondencia. ${ }^{41}$ Por cierto, nada de malo hay en esforzarse por establecer puentes entre lo que se decide mediante las sentencias judiciales y lo que ocurre en el mundo, siempre que respecto a esto último se cuente con la suficiente claridad acerca de qué es lo que estaría implicado en el contexto de los procesos judiciales. ${ }^{42}$ Acorde a ello, el concepto de "hechos" asumido por las teorías cognoscitivistas establece una correlación estrecha entre lo que es el producto de la decisión judicial que se extrae desde la condición de aplicación de una o más normas jurídicas, y lo que sería un resultado epistémicamente válido en contextos tan exigentes como el científico. Así las cosas, la única manera de producir tales resultados pasaría por disponer de una tecnología que evite - o al menos controle significativamente ${ }^{43}$ — desviaciones del punto de llegada. En lo que sigue, agruparemos tales desviaciones recurriendo a los rótulos de falsedad, error, falsificación e insuficiencia. Al respecto, dice Eco: "Para decir que una cosa es errónea, o falsa, o que es producto de una falsificación, hay que tener previamente una idea de lo que es correcto, o verdadero o auténtico". ${ }^{44}$ Sin embargo, si miramos las cosas desde el otro lado del espejo que es el que aquí interesa- debiéramos prestar atención a la posición correlativa, esto es: para decir que una cosa es correcta verdadera o auténtica, hay que tener previamente una idea de lo que es erróneo, o falso, o que es producto de una falsificación. Respecto de la categoría de insuficiencia se considerará la variable temporal y un análisis de posibilidades dependiente del contexto en que se esté operado. El binomio a tener en cuenta es suficiencia insuficiencia.

\section{Sobre niveles de desarrollo como variables que determinan el éxito de las teorías en asuntos de prueba y acerca de cómo identificarlos}

Salvo casos patológicos, el éxito de las teorías de la prueba resulta de su compatibilidad con/u orientación hacia un estado de cosas ventajoso respecto al esperable del uso del mero sentido

\footnotetext{
afirma: "El proceso judicial es, en algún sentido, un rito contra la incertidumbre [...] Que sea un rito nos indica en gran medida cierta vocación del proceso para comprometerse "falsamente" con la disolución de la incertidumbre [...] Siempre viviremos con dudas acerca de nuestros objetos de atención”. VALENZUELA (2017), p. 17.

${ }^{40} \mathrm{El}$ asunto, por cierto, es extensible a las humanidades. WILLIAMS (2006), p. 22.

${ }^{41}$ La formulación clásica — como se sabe - se encuentra en Aristóteles "Falso es, en efecto, decir que lo que es, no es, y que lo que no es, es; verdadero, que lo que es, es, y que lo que no es, no es" ARISTÓTELES (2011), p. 171. Una revisión de la teoría que ha sido la principal responsable de su revitalización se encuentra en TARSKI (1960), pp. 111-157.

42 Desde una perspectiva mucho más amplia BOHM (2018), pp. 99-103.

${ }^{43}$ Esto queda ilustrado en el siguiente fragmento: "Un fracaso en la determinación de la verdad —mientras sea excepcional - no invalida la decisión del juez, que es considerada válida y produce por ende todos sus efectos jurídicos. Este es el precio que el derecho está dispuesto a pagar en aras de la seguridad y de la paz social, esto es poder resolver los conflictos sociales dentro de ciertos límites temporales". ALCHOURRÓN y BULYGIN (1991), p. 313.

${ }^{44}$ ECO (2018), p. 227.
} 


\section{Polít. Crim. Vol. 15, No 30 (Diciembre 2020), Art. 4, pp. 614-638 \\ [http://politcrim.com/wp-content/uploads/2020/10/Vol15N30A4.pdf]}

común $^{45}$; ello, por cierto, en lo que concierne a la gestión de las pruebas y a la decisión de los hechos. En pocas palabras, la aplicación de una teoría debiera dar garantías en orden a que es dable esperar que: a) los resultados a los que conduce son mejores (en alguno de los sentidos de esta escurridiza palabra) en lo que atañe a la atribución de conductas a sujetos que calzan en determinadas categorías jurídicamente relevantes; b) los procedimientos utilizados son más estandarizados y; c) el control sobre la prueba presentada en las audiencias respectivas es más riguroso.

Dependiendo del nivel de logro que ofrezca una propuesta de teoría en cada una de las variables señaladas, podríamos sostener que conducen al progreso del campo de trabajo o bien, a su adaptación con el entorno social. Una tercera posibilidad es la de estancamiento, la que se produciría cuando la teoría no se encuentra en condiciones de ofrecer una forma de operar que resulte preferible a la mera aplicación del sentido común (en este sentido, el estancamiento debiera conducir a un fracaso de la propuesta).

Una teoría de la prueba plausible debiese fijar sus expectativas (cauta o arriesgada) a la luz de los métodos y saberes desarrollados o asimilados por la comunidad disciplinaria; ello con miras a decidir si las conjeturas en competición en un proceso judicial se encuentran o no probadas. De esta forma, es preciso tener en cuenta, por una parte, la calidad estándar de los soportes probatorios generados en las audiencias ${ }^{46}$, junto a prácticas asentadas para construir relaciones entre pruebas y conjeturas factuales relevantes; y por la otra, la calidad de los resultados producidos y su relación con el entorno. En el siguiente cuadro se ilustra lo recién señalado:

\footnotetext{
${ }^{45}$ GEERTZ (1999), pp. 105-114. Ver también SANDOVAL (publicación pendiente, citado con permiso del autor).

${ }^{46}$ COLOMA (2019), pp. 438-443.
} 


\begin{tabular}{|c|c|c|c|}
\hline $\begin{array}{l}\text { Nivel desarrollo / } \\
\text { Variables relevantes }\end{array}$ & $\begin{array}{l}\text { Soportes extraíbles } \\
\text { de audiencias de } \\
\text { prueba }\end{array}$ & $\begin{array}{l}\text { Mecanismos que } \\
\text { construyen } \\
\text { relaciones } \\
\text { probatorias }\end{array}$ & $\begin{array}{l}\text { Productos y } \\
\text { relación con } \\
\text { entorno social }\end{array}$ \\
\hline Progreso & $\begin{array}{l}\text { Producción } \\
\text { exhaustiva y } \\
\text { detección de } \\
\text { falsificaciones } \\
\text { (ausencia de lagunas } \\
\text { de información y } \\
\text { disponibilidad de } \\
\text { tecnologías que } \\
\text { aseguran } \\
\text { autenticidad) }\end{array}$ & $\begin{array}{l}\text { Lenguaje técnico } \\
\text { con alto control } \\
\text { disciplinario (uso } \\
\text { regular de modelos } \\
\text { y/o algoritmos) }\end{array}$ & $\begin{array}{l}\text { Hechos estables } \\
\text { externamente y } \\
\text { demostraciones } \\
\text { replicables } \\
\text { (coordinación con } \\
\text { ciencias y otras } \\
\text { disciplinas) }\end{array}$ \\
\hline Adaptación & $\begin{array}{l}\text { Producción } \\
\text { satisfactoria y } \\
\text { posibilidad de } \\
\text { refutación (reacción } \\
\text { ante patologías) }\end{array}$ & $\begin{array}{l}\text { Lenguaje natural } \\
\text { controlable lógica } \\
\text { y culturalmente } \\
\text { (esfuerzo narrativo } \\
\text { y ético) }\end{array}$ & $\begin{array}{l}\text { Hechos estables y } \\
\text { abiertos a } \\
\text { escrutinios externo } \\
\text { (conciencia de } \\
\text { limitaciones) }\end{array}$ \\
\hline Estancamiento & $\begin{array}{l}\text { Incapacidad de } \\
\text { distinguir calidad de } \\
\text { pruebas (ausencia } \\
\text { criterios } \\
\text { jerarquización) }\end{array}$ & $\begin{array}{l}\text { Lenguaje natural } \\
\text { carente de control } \\
\text { textual } \\
\text { (corazonadas, } \\
\text { revelaciones) }\end{array}$ & $\begin{array}{l}\text { Hechos carentes de } \\
\text { control externo } \\
\text { (dogmatismo, } \\
\text { animismo) }\end{array}$ \\
\hline
\end{tabular}

La estrategia que usaré para identificar el estado en que nos encontramos supone prestar atención a los mecanismos previstos en el sistema jurídico para la modificación de las decisiones probatorias adoptadas. La elección de dicho momento se explica por cuanto aquellos operan solo una vez que se han confrontado puntos de vista rivales (cada uno intentando maximizar sus posibilidades) y habiéndose incurrido en costes elevados. ${ }^{47}$ Entre todos ellos resultan especialmente ilustrativos los previstos en el ámbito penal, en cuanto al menos teóricamente - es más sensible al problema de los errores, falsedades, falsificaciones e insuficiencias probatorias. Así las cosas, en lo que sigue fijaré la atención en las distintas causales previstas para la acción de revisión ${ }^{48}$, y en una de las causales del

\footnotetext{
${ }^{47}$ No debemos olvidar que una de las variables relevantes para decidir si seguir adelante con un proceso judicial, tiene que ver con sus costes. El asunto debe ser enfatizado ya que eso genera mayores expectativas de corrección que las que serían de esperar de un simple ejercicio de confrontación de ideas en el que no se está dispuesto a invertir cifras relevantes de dinero con miras a salir victorioso. Las disposiciones las tomo del sistema jurídico chileno que no parece diferir especialmente de otros países de la tradición del Civil Law.

${ }^{48}$ Los problemas que, en concreto, se zanjan por vía de acción de revisión constituyen solo una pequeña muestra de lo que, en términos más amplios implicaría hacerse cargo (a cabalidad) del proceso judicial, como herramienta que garantiza que los culpables serán condenados y los inocentes, absueltos. El problema de la falta de cobertura, por cierto, es extensible a otros países. DUCE (2015), pp. 162-165.
} 


\section{Polít. Crim. Vol. 15, No 30 (Diciembre 2020), Art. 4, pp. 614-638 [http://politcrim.com/wp-content/uploads/2020/10/Vol15N30A4.pdf]}

recurso de nulidad. ${ }^{49}$ Las causales que tendré en cuenta son, en el caso de la acción de revisión, las previstas en el art. 473, letras a) hasta e) del Código Procesal Penal (en adelante $\mathrm{CPP}),{ }^{50}$ es decir, no se excluye ninguna de las posibilidades allí previstas. En el caso del recurso de nulidad, en cambio, solo se tendrá en consideración la del art 374 letra e), en cuanto remite al art. 342 letra c) y 297 del CPP. Aquello obedece a que es la única causal asociada a la nulidad que entra de lleno en asuntos de carácter probatorio. ${ }^{51}$

El análisis que se realizará a continuación no pretende dar cuenta de las vastas posibilidades que arrojan tales disposiciones, sino simplemente esbozar un mapa provisional de diferentes situaciones que nuestro sistema jurídico considera valioso mantener controladas. El punto es importante dado que debiera iluminar acerca de qué es lo que cabe esperar de una teoría de la prueba atractiva tanto para jueces, como para litigantes. Las categorías que - a mi juiciopueden construirse para dar cuenta de lo planteado por las disposiciones aludidas tienen en consideración tres componentes, a saber: resultados, métodos y pruebas que han de servir de soporte. El fracaso, en el primero de los casos se asocia al concepto de falsedad; en el segundo, al concepto de error (metodológico y actitudinal); y en el tercero, a la falta de autenticidad (falsificación) e insuficiencia probatoria. ${ }^{52}$ Los casos de falsedad se asocian con lo que se indicará en el punto 3.1. Los casos de error se vinculan con los puntos 3.2 y 3.3. En el primero de ellos, el error se relaciona con la estructura narrativa o lógica del texto que correlaciona las pruebas con los hechos, y en el segundo, con la posición subjetiva del decisor (virtudes). Los casos de falsificación se conectan con el punto 3.4 subsiguiente. Los casos del punto 3.5., en rigor, son consecuencia de la consideración de la variable"tiempo" y, como tales, no constituyen un problema de falsedad, error o falsificación en que pudiere haber incurrido el juzgador, sino de insuficiencia de las pruebas desde las cuales se decidió. El efecto, sin embargo, presenta cierta familiaridad con la falsificación; ello en cuanto resulta palmario que no se dispuso de la mejor prueba potencialmente disponible al momento de adoptar la decisión de si la conjetura en competencia se encontraba o no probada y, es preciso, entonces, replanteársela a la luz de la nueva información.

\subsection{Resultados que tensionan con lo verdadero (o descartables en razón de su falsedad)}

\footnotetext{
${ }^{49}$ Se toma en cuenta lo previsto en el sistema jurídico chileno. Aquello no lleva, sin embargo, a que la mirada sea puramente local, pues lo que se dice en sus disposiciones no parece ser demasiado diferente a lo que ocurre en otros países de Iberoamérica.

${ }^{50}$ FERNÁNDEZ y OLAVARRÍA (2018), pp. 1277 analizan el período 2007-2017 y no detectaron ninguna acción de revisión que acogiera las causales de las letras a), b), c) y e) del art. 473 del CPP.

${ }^{51}$ Otras causales del recurso de nulidad que puede ser interesante tener en consideración son las del art. 373 letra a) y 374 letra f), dadas sus potenciales implicaciones en asuntos probatorios, por ejemplo, al hacerse cargo de asuntos tales como el de la ilicitud de la prueba o de la posibilidad de refutar en condiciones adecuadas aquello que pretende ser demostrado. El análisis de ellas, sin embargo, excedería los propósitos de este trabajo, pues resultan muy abiertas.

${ }^{52}$ Una estructura distinta de ordenación de las causales de la acción de revisión puede verse en MAÑALICH (2020), pp. 40 y ss. El criterio básico de diferenciación allí utilizado se hace depender de la existencia de una injusticia, ya sea, sustantiva o procedimental. Solo en el primero de los casos podría entenderse que se ha condenado a un inocente, en términos fuertes, o si se prefiere se ha incurrido en un falso positivo. En el caso de la injusticia procedimental —al ser de carácter imperfecta según la terminología rawlsiana- solo se ha aumentado el riesgo de una injusticia sustantiva. Para Mañalich la injusticia sustantiva propiamente tal concurre en las causales b) y d) del art. 473 del CPP. Más allá del uso de una terminología diferente — y a la luz de lo que a continuación sostendré - es evidente que tenemos con Mañalich un desacuerdo interpretativo respecto a lo implicado en las letras a) y d) de la aludida disposición del CPP.
} 


\section{Polít. Crim. Vol. 15, No 30 (Diciembre 2020), Art. 4, pp. 614-638 [http://politcrim.com/wp-content/uploads/2020/10/Vol15N30A4.pdf]}

El problema consiste en que el resultado al que se llega en la respectiva sentencia es incompatible con nueva información que posteriormente se llegue a disponer. Las disposiciones que tratan directamente de aquello son las letras a) y b) del artículo 473 del $\mathrm{CPP}$, según el cual:

“(L)a Corte Suprema podrá rever extraordinariamente las sentencias firmes en que se hubiere condenado a alguien por un crimen o simple delito, para anularlas, en los siguientes casos:

a) Cuando, en virtud de sentencias contradictorias, estuvieren sufriendo condena dos o más personas por un mismo delito que no hubiere podido ser cometido más que por una sola;

b) Cuando alguno estuviere sufriendo condena como autor, cómplice o encubridor del homicidio de una persona cuya existencia se comprobare después de la condena."

El calificativo de falso adquiere pleno sentido en razón de su incompatibilidad con otro hecho no problematizado. No se duda, por una parte, que si hay dos personas encarceladas por un mismo delito que solo una pudo cometer, a lo menos, en uno de los casos será falso que uno de los condenados realizó la conducta punible; y por la otra, si la persona cuya muerte se dio por probada se encuentra viva, será falso que el condenado la mató. Estos casos resultan especialmente prometedores para las teorías cognoscitivistas, pues la fuerza que cabe reconocer a lo que se declara como falso alimenta posibilidades de contar con un concepto de hechos estrechamente conectado con una idea de verdad como correspondencia. En otras palabras, el problema aquí presentado propende a que se opere bajo el binomio verdadero falso; ello en razón de que, a lo menos, se dispone de un par de ejemplares abstractamente formulados que cabría incluir en la categoría de falsos. ${ }^{53}$

\subsection{Mecanismos que tensionan con lo narrativamente correcto (o descartables por haberse incurrido en un error)}

El problema del cual trata de hacerse cargo es que el discurso de justificación no resulta satisfactorio, salvo que se cuente con criterios de validación que deban respetarse con miras a alcanzar determinadas conclusiones. Si analizamos los mecanismos del proceso penal para modificar lo erróneamente decidido, podríamos remitirnos al recurso de nulidad, específicamente a la causal de la letra e) del artículo 374, que remite a los arts. 342 letra c) y 297 del CPP. Una reconstrucción lingüísticamente conservadora ${ }^{54}$ se plantea en la siguiente formulación:

\footnotetext{
${ }^{53}$ Es importante tener en consideración que para la atribución del estatus de contradictorias a dos sentencias, se requiere ejecutar una tarea interpretativa en concreto, acerca de la incompatibilidad de las narrativas de los respectivos textos. Así, por ejemplo, en sentencia de la Corte Suprema Rol 8316-2014 de 28 de abril de 2014 se rechaza acción de revisión interpuesta por Pedro Rocca, a pesar de que en el texto de la primera de las sentencias se indica que el condenado por robo por homicidio, lo es en calidad de autor único. La acción fue rechazada, dadas las circunstancias en las que se cometió el delito. De hecho, en la primera de las sentencias a pesar de condenar a solo una persona por el robo con homicidio - no se excluye la participación de quien fue finalmente condenado en la segunda de las sentencias. Un análisis de este mismo caso, en términos de distinguir entre hechos y descripciones de hechos puede verse en FERNÁNDEZ y OLAVARRÍA (2018), pp. 1277 - 1279.

${ }^{54}$ Las modificaciones en la sintaxis y en el léxico tratan de reducirse al mínimo.
} 


\section{Polít. Crim. Vol. 15, No 30 (Diciembre 2020), Art. 4, pp. 614-638 [http://politcrim.com/wp-content/uploads/2020/10/Vol15N30A4.pdf]}

"El juicio y la sentencia serán siempre anulados cuando, en la sentencia, se hubiere omitido la exposición clara, lógica y completa de cada uno de los hechos y circunstancias que se dieren por probados, fueren ellos favorables o desfavorables al acusado, y de la valoración de los medios de prueba, la que no deberá contradecir los principios de la lógica, las máximas de la experiencia y los conocimientos científicamente afianzados.

La fundamentación deberá hacerse cargo de toda la prueba producida, incluso de aquélla que se hubiere desestimado, indicando en tal caso las razones que hubiere tenido en cuenta para hacerlo. Asimismo, requerirá el señalamiento del o de los medios de prueba mediante los cuales se dieren por acreditados cada uno de los hechos y circunstancias que se dieren por probados. Esta fundamentación deberá permitir la reproducción del razonamiento utilizado para alcanzar las conclusiones a que llegare la sentencia".

El foco para hacerse cargo de una nueva dupla que sería la de correcto - erróneo tiene que ver fundamentalmente con el procedimiento seguido para alcanzar un cierto resultado. Por ejemplo, si dos personas han aplicado el mismo procedimiento, pero han llegado a un resultado diferente, resulta sensato examinar las actividades realizadas con miras a identificar en qué parte de la secuencia, uno de ellos se apartó de lo que resultaba esperable. Un procedimiento altamente regulado haría mucho más fácil encontrar aquello que ha sido incumplido en comparación a uno en que abundan las libertades. Según lo expresado, un hecho es erróneo cuando su validez no se puede hacer derivar de una cierta metodología reconocida como apta para su producción.

El principal problema de lo previamente señalado, radica en la validación de la metodología a seguir. ${ }^{55}$ En ámbitos en los cuales se podría afirmar que se ha alcanzado un estado de progreso, hay formas de identificar errores metodológicos. ${ }^{56}$ Ello supone que se puede verificar la validez del resultado, ya sea por observación directa, por la obtención de contramuestras o por la aplicación de otros procedimientos. Así, por ejemplo, podremos decir que la predicción de un eclipse es errónea si llegado el día y hora en que debía ocurrir este no se produce, o bien que un cálculo es erróneo si vuelto a realizar los resultados difieren. Este no es el caso de los procesos judiciales en los que de lo que se trata es de hacer una buena evaluación de las posibilidades disponibles. En los procesos judiciales, el binomio correcto - erróneo no requiere de una concepción de verdad como correspondencia, siéndole suficiente una forma de control sobre la narrativa utilizada. ${ }^{57}$ Lo que se requiere es sacar el

\footnotetext{
${ }^{55}$ Una manifestación de esto la constituye el conocido reclamo de Larry Laudan en orden a que si un estándar de prueba es subjetivo, no sería propiamente un estándar. LAUDAN (2005), pp. 99 y ss.

${ }^{56}$ Debe tenerse en cuenta que disciplinas suficientemente reconocidas en lo que concierne a la producción de datos que confirman las teorías deben lidiar con una serie de problemas para lograr entre ellos una "concordancia razonable", KUHN (1993), pp. 208 y ss.

${ }^{57}$ En rigor, la detección de esta clase de errores no requiere de herramientas que aseguren que estamos más próximos a lo que habría sido la conducta que se trata de dilucidar. De lo que se trata es simplemente es que la narrativa que, en concreto ha sido elegida argumentativamente es insatisfactoria por no hacerse cargo de la calidad de los soportes de las conclusiones o por realizar saltos inferenciales superiores a lo tolerable. Vale la pena considerar que en la India Antigua una importante escuela de argumentación solo apuntaba a la detección de los errores, pero no se pronunciaba respecto a si aquello algo tenía que ver con una correcta representación de la realidad. Ver ARNAU (2008), pp. 51-54.
} 


\section{Polít. Crim. Vol. 15, No 30 (Diciembre 2020), Art. 4, pp. 614-638 [http://politcrim.com/wp-content/uploads/2020/10/Vol15N30A4.pdf]}

máximo provecho a las distintas piezas de las que se asume hay que hacerse cargo, dentro de lo narrativamente tolerable ${ }^{58}$.

\subsection{Mecanismos que tensionan con la posición subjetiva esperable del juzgador (o descartables por un vicio de falta de imparcialidad)}

Refiere a problemas relativos a la posición subjetiva de imparcialidad que sería exigible a los jueces que deciden hechos. Para ello, es relevante la letra e) del artículo 473:

“e) Cuando la sentencia condenatoria hubiere sido pronunciada a consecuencia de prevaricación o cohecho del juez que la hubiere dictado o de uno o más de los jueces que hubieren concurrido a su dictación, cuya existencia hubiere sido declarada por sentencia judicial firme."

En rigor lo que aquí preocupa no es el resultado alcanzado sino la manera en que aquel fue obtenido. De esta manera, la sentencia anulada podría haber sido consistente con aquello a que las pruebas disponibles apuntaban (e, incluso, con la conducta que se intentaba desentrañar), pues la parte que ofreció una cantidad de dinero, por ejemplo, era la misma que debía obtener una decisión favorable si se hubieren hecho correctamente las cosas, pero temía que el tribunal fallase en su contra. Hay, entonces, una actitud ético-jurídica esperada del juzgador que se pretende resulte debidamente resguardada, incluso si no hay indicios de falsedad ni de error en la manera de construir narrativamente la sentencia. En otras palabras, de lo que se trata es de resguardar virtudes en el juzgador, lo cual comunica que los hechos probados no se conciben de una manera totalmente aislada del sujeto que tomó la decisión respectiva. ${ }^{59}$ Ello va de la mano de que lo que aquí importa excede claramente lo pretendido por una concepción de verdad como correspondencia. ${ }^{60}$

\subsection{Soportes que tensionan con lo auténtico (o descartables por el uso de prueba falsificada)}

El problema del que precisa hacerse cargo es de la aparición de nuevas pruebas que deslegitiman a las que fueron utilizadas en el momento de la decisión probatoria. La letra c) del artículo 473 aclara:

“c) Cuando alguno estuviere sufriendo condena en virtud de sentencia fundada en un documento o en el testimonio de una o más personas, siempre que dicho documento o dicho testimonio hubiere sido declarado falso por sentencia firme en causa criminal."

Este caso da cuenta directa del binomio auténtico - falsificado. En cuanto a esto último, se trata de algo que no contaba con los méritos para ser considerado como soporte a un hecho, pese a lo cual ha ocupado ese lugar en razón de un acto positivo conducente a provocar

\footnotetext{
${ }^{58}$ COLOMA (2011), p. 75-97. También COLOMA y AGÜERO (2014), pp. 673-703.

${ }^{59}$ Un panorama general de las posibilidades ofrecidas por las teorías de la virtud respecto de distintos ámbitos de la toma de decisiones judiciales puede verse en AMAYA (2015), pp. 1758-1810. Un análisis específico de la epistemología de las virtudes para el razonamiento probatorio puede verse en AMAYA (2017), pp. 19-36.

${ }^{60}$ Para POPPER (1989), p. 276, la circunstancia de que un sujeto formule una determinada aserción no influye en absoluto sobre su estatus de verdadera.
} 


\section{Polít. Crim. Vol. 15, No 30 (Diciembre 2020), Art. 4, pp. 614-638 [http://politcrim.com/wp-content/uploads/2020/10/Vol15N30A4.pdf]}

engaño. ${ }^{61}$ Hay, entonces, en el origen de esta causal una apariencia que hizo que se tomase en serio un dato que en rigor no cumplía con las exigencias de legitimidad de los procesos judiciales, y que al día de hoy ha sido revelada. Esta causal, entonces, resguarda que las piezas de información que adquieren el estatus de soporte permanezcan en interinidad frente a la posibilidad de que sea demostrada una falsificación. ${ }^{62}$

\subsection{Soportes que tensionan con lo potencialmente disponible (o que son descartables por insuficiencia de la prueba).}

Refiere al problema de la aparición de nuevas pruebas que compiten con las que fueron utilizadas en el momento de la decisión probatoria. Nuevamente, en el art. 473 del CPP se habla que procederá la revisión:

“d) Cuando, con posterioridad a la sentencia condenatoria, ocurriere o se descubriere algún hecho o apareciere algún documento desconocido durante el proceso, que fuere de tal naturaleza que bastare para establecer la inocencia del condenado."

El foco en este caso se sitúa en la circunstancia de que la clausura de la discusión — propia de la decisión sobre hechos- debe ser dejada de lado si en el futuro se llega a disponer de nueva prueba que haga insostenible perseverar en lo que en el pasado fue dicho ${ }^{63}$. Lo expresado tiende un puente con la llamada cuestión abierta de la que se habla en el mundo científico (y que, por cierto, es transferible hacia otras disciplinas que se hacen cargo del pasado). El descubrimiento de un nuevo hecho o la aparición de un documento desconocido no demuestran propiamente la falsedad de la decisión que fue adoptada en su momento, sino que la debilitan. En otras palabras, aquello que en su momento se estimó suficiente para dar por superadas las exigencias de un estándar de prueba, ahora ha dejado de serlo. En un estado de progreso, la aparición de nueva prueba, una vez que las sentencias han adquirido el estatus de cosa juzgada debiera ser algo excepcional, pues debiera disponerse de suficientes herramientas para detectar todos los soportes probatorios relevantes. Si aquello no ocurre y, en cambio, regularmente aparece prueba con posterioridad a la dictación de la sentencia de término, la idea de verdad como correspondencia en cuanto categoría que impregna una teoría de la prueba asentada, resulta difícil de mantenerse en pie. ${ }^{64}$

\footnotetext{
${ }^{61}$ Un análisis sobre la credibilidad de las pruebas que distingue variables de autenticidad, exactitud y fiabilidad, puede verse en ANDERSON et al. (2015), pp. 98-107.

${ }^{62} \mathrm{El}$ resguardo ante lo falsificado resulta clave para establecer diferencias con el lenguaje de lo ficcional. Para este último, no existe un control sobre el soporte del argumento que se desarrolla, pero sí —salvo por ejemplo en el teatro del absurdo - sobre las conexiones para arribar a ciertas conclusiones. Un buen ejemplo se puede ver en el análisis de Auerbach respecto de los detalles a través de los cuales Homero hace que el reconocimiento de Euriclea sobre Ulises a partir de una cicatriz que toca al lavar sus pies, resulte narrativamente justificado. AUERBACH (1996), pp. 9-13.

${ }^{63}$ Un asunto problemático de esta causal se relaciona con la dificultad de evaluar el impacto de la nueva prueba en lo que habría sido el juicio originariamente realizado: la audiencia no es vuelta a realizar por lo que es difícil analizar el impacto de la nueva prueba en el conjunto de datos que, en su momento, estuvieron disponibles. Así se ha hablado de "contexto epistémico defectuoso", FERNÁNDEZ y OLAVARRÍA (2009), p. 237.

${ }^{64}$ Las investigaciones de Duce, y de Fernández y Olavarría, muestran que ésta es, por muy lejos la causal que lleva a la Corte Suprema a acoger acciones de revisión. A su vez, la mayoría de los casos corresponden a suplantación de personas. En concreto, se trata de casos en que el condenado - generalmente detenido en flagrancia - entrega a la policía un documento de identidad que no es el propio. Duce indica que de las 44
} 


\section{Breve discusión sobre los problemas de las teorías cognoscitivistas y de las ventajas de operar con teorías más modestas}

A las teorías cognoscitivistas —en razón de sus pretensiones fuertes de hacerse cargo de la realidad — no les está permitido eludir el viejo — y aparentemente insoluble — problema de la demarcación. ${ }^{65}$ En el caso que aquí interesa, aquello supone distinguir entre lo que es conducente al conocimiento del pasado y aquello que no lo es. Tales expectativas no resultan particularmente seductoras para sujetos eminentemente estratégicos, como es el caso de los litigantes. Ellos prestarán atención a las teorías de la prueba, solo en la medida que los resultados a que su uso conduzca resulten más persuasivos que los que por sí mismos están en condiciones de construir autónomamente, valiéndose solo de un poco de imaginación. Por su parte, los jueces estarán llanos a abrirse al uso de teorías cognoscitivistas (mediadas o no por abogados) bajo la condición de que les otorguen más seguridad — entendida en su dimensión de inmunidad a la crítica o de protección ante las sanciones- que los resultados a los que llegarían si, lisa y llanamente, fueren cautelosos en su tarea de construir los discursos mediante los cuales justifican sus decisiones. Si en los tiempos que corren no se ha llegado a alcanzar un estado de progreso, las teorías cognoscitivistas no estarían en condiciones de ofrecernos un punto de partida suficientemente atractivo.

Para dirimir el estado de desarrollo en que nos encontramos volquemos la atención, por un momento, en los binomios o pares de opuestos: verdadero - falso / correcto - erróneo / auténtico - falsificado / (prueba) suficiente - (prueba) insuficiente. Huelga decir que las fronteras entre ellos distan de ser nítidas y, en consecuencia, un análisis exhaustivo precisaría hacer algunas estipulaciones. Lo interesante es que al prestar atención en la regulación de aquellas situaciones cuya gravedad lleva a modificar lo que ha sido resuelto por un tribunal, podemos tener mejores pistas de qué es lo que realmente se pretende al dar por probados (o no) ciertos hechos y cuál sería el papel que podría desempeñar en ese contexto una concepción de verdad como correspondencia, frente a opciones como las ofrecidas, por ejemplo, por la concepción de la verdad como coherencia ${ }^{66}$ u otras en que el concepto de verdad muta en irrelevante. ${ }^{67}$

Una concepción que se sostenga en la plausibilidad de la dupla verdadero - falso en un sentido fuerte, tiene que proveer de herramientas que otorguen estabilidad a lo que se presenta como manifestación de lo externo. El binomio verdadero - falso resulta atractivo en la

acciones de revisión acogidas en el período 2007 a 2013, 36 correspondieron a suplantación de identidad. DUCE (2015), pp. 176-178. Los cuatro casos asociados a problemas de reconocimiento ocular defectuoso pueden verse en DUCE (2018), pp. 149-208. FERNÁNDEZ y OLAVARRÍA (2018), p. 1214, muestran que en el período bajo examen, 42 de 54 acciones de revisión acogidas se trataron de casos de suplantaciones de identidad.

${ }^{65}$ El problema de la demarcación implica aceptar anticipadamente que se puede estar equivocado. Asumirlo seriamente supone anticipar cuáles constituirían algunos de los errores que harían que la teoría sea falsa. Esto, junto a la osadía de los planteamientos, es un asunto importante para la aceptación de una teoría, lo que no obsta que constituya, a la vez, una actitud heroica. POPPER (2013), pp. 131 y ss.

${ }^{66}$ Una muestra sencilla puede verse en MACCORMICK (1980), pp. 45-50. Para una reconsideración del rol del concepto de verdad como categoría clave, y su sustitución por la de aceptabilidad racional, ver HABERMAS (2002), p. 130.

${ }^{67}$ RORTY (2000), pp. 11 y ss. 


\section{Polít. Crim. Vol. 15, No 30 (Diciembre 2020), Art. 4, pp. 614-638 [http://politcrim.com/wp-content/uploads/2020/10/Vol15N30A4.pdf]}

medida que nos habilita para clausurar discusiones hasta un momento en que aparezcan nuevos datos incompatibles con las conclusiones aceptadas o bien formas de interpretación más sofisticadas que resultan más profundas y/o abarcadoras que las de antaño. Los desaciertos en relación a lo que es verdadero y lo que es falso debieran constituir situaciones excepcionales. Así, debiera disponerse de formas de experimentación que arrojen resultados estables para diferentes observadores y, a la vez, tendría que llegar a una forma de coordinación con otras disciplinas que dispongan de una tecnología consolidada. Según lo que hemos anticipado, las causales de acción de revisión que apuntan en esta dirección indican los fallos en que se incurriría (¿Cuándo se han hecho mal las cosas?), pero no garantizan los aciertos (¿Cuándo se han hecho bien las cosas?). La disponibilidad de exámenes como el de ADN, por cierto, estimulan una cierta dosis de optimismo respecto del uso de estas categorías, pero según ha sido adelantado el campo de aplicación es bastante reducido, y no contándose con una batería tecnológica adicional, resultaría distorsionador reconstruir nuestras prácticas como guiadas por la determinación de lo que es verdadero y lo que es falso. ${ }^{68}$

A excepción de unos pocos casos en que se cuenta con una tecnología avanzada (por ejemplo, el recién aludido examen de $\mathrm{ADN}$ ), en lo que atañe a la gestión de las pruebas y a la toma de decisiones judiciales, habrá que recurrir al análisis de las narrativas implicadas en las declaraciones de testigos y peritos, alegatos de abogados y sentencias de tribunales. En otras palabras, habrá que poner la atención a variables, tales como, coherencia, completitud y coordinación entre distintas clases de discursos ${ }^{69}$, asumiendo las posibilidades ofrecidas por el contexto en cada caso $^{70}$. Y todo ello, por cierto, resulta muy difícil de domesticar para las teorías cognoscitivistas.

Pese a lo señalado, tiene sentido para nosotros hablar de lo verdadero y de lo falso — al igual que para cualquier comunidad - aun cuando se carezca de herramientas tecnológicas avanzadas. $^{71}$ Con esta distinción lo que intentamos no es tanto comunicar que hemos desentrañado cómo es el mundo, sino más bien que el esfuerzo desplegado —asumiendo nuestro estado actual de desarrollo - provee de una garantía suficiente para no tener que estar revisando continuamente nuestras decisiones. En ese orden de cosas, es importante tener en cuenta que la ontología y la epistemología que elijamos son interdependientes, es decir, nuestra imagen de mundo es dependiente del conocimiento que seamos capaces de construir, y el conocimiento que construyamos condicionará nuestra imagen del mundo. ${ }^{72}$ En términos más cercanos a lo que aquí interesa, si, por ejemplo, las formas de producción de

\footnotetext{
${ }^{68}$ Según Fernández y Olavarría en el período 2007 a 2017, la Corte Suprema chilena tramitó solo un recurso en que se invocó prueba de ADN, siendo éste finalmente rechazado. FERNÁNDEZ y OLAVARRÍA (2018), pp. $1240-1243$.

${ }^{70} \mathrm{El}$ registro narrativo que se espera utilicen testigos, peritos, abogados y jueces es diferente. De algunos se espera una forma de comunicación muy neutral, como si se tratase de un cronista (testigos); en otros, las expectativas apuntan a la exploración de diversas posibilidades que sean consistentes con los intereses de la parte cuyos intereses representan (abogados), etc. Pero, incluso, habrá particularidades según sea el caso del que se trate: así, por ejemplo, en situaciones en las cuales se persigue construir/preservar la memoria histórica, los testigos debieran también explorar posibilidades que ayuden a explicar por qué sucedió lo que se dice que sucedió.

${ }^{71}$ ECO (2012), p 49.

72 ARNAU (2017), pp. 262-264.
} 


\section{Polít. Crim. Vol. 15, No 30 (Diciembre 2020), Art. 4, pp. 614-638 [http://politcrim.com/wp-content/uploads/2020/10/Vol15N30A4.pdf]}

conocimiento se ocupan eminentemente de reconstruir relatos coherentes con nuestras expectativas de auto-comprensión comunitaria, el resultado que alcancemos (si hacemos bien las cosas) debiera ser consistente con la imagen que de nosotros mismos hemos ido forjando: nada más, pero tampoco, nada menos.

El binomio correcto - erróneo se construye teniendo como referente las conexiones entre un punto de partida no problematizado y el punto de llegada al que se arriba, siguiendo una cierta secuencia. Salvo cuando, excepcionalmente, se incorporan algunos algoritmos provistos por peritos de otras disciplinas en las sentencias de jueces y alegatos de abogados, nuestras conexiones dependerán del uso más o menos riguroso de las posibilidades que nos ofrecen los lenguajes naturales. La escasa estandarización de nuestros métodos resulta palmaria al observar nuestra disposición a aceptar discursos discrepantes en las sentencias dictadas por tribunales colegiados, bajo la sola condición de que estén cuidadosamente construidos. De esta manera, las relaciones posibles nos parecen múltiples y la crítica emergerá solo en el caso de que advirtamos falacias argumentativas. Así las cosas, más que un método que conduzca regularmente a determinados resultados, lo que nos interesa es que el argumento esté bien construido, independiente del resultado al que nos conduzca. Si el diagnóstico no resulta errado, lo que a este nivel interesa no es una correspondencia con el mundo, sino una forma de comunicación que resulte de la práctica de ciertas virtudes como la honestidad, la rigurosidad o la humildad epistémica, ${ }^{73}$ o bien con ciertas características de los textos construidos como es el caso de la coherencia, la completitud o la precisión. ${ }^{74}$

La dupla auténtico - falsificado constituye una aproximación que suscita bastante interés entre litigantes y jueces. Aparte de la relevancia, constituye un filtro especialmente valorado entre aquello que puede ser usado y lo que carece de credenciales. La razón parece simple: es un asunto al que diariamente nos vemos expuestos en nuestras vidas y tenemos clara conciencia de la fragilidad que le aqueja especialmente en lo que refiere a la prueba de testigos de la cual no estamos en condiciones de prescindir. ${ }^{75}$ Los avances que al respecto se han ido produciendo al cabo de milenios claramente resultan poco significativos. ${ }^{76}$ Las herramientas de las que disponemos para controlar testigos que mezclan recuerdos ${ }^{77}$ o que abiertamente mienten acerca de lo que creen haber percibido, no resultan todavía lo suficientemente útiles para establecer una frontera entre las categorías de auténtico y

\footnotetext{
${ }^{73}$ BAEHR (2015), pp. 57-161; DE BRASI (2020), pp. 142-161.

${ }^{74}$ En cuanto al método de producción de correlaciones es ilustrativo que los juristas no hayan prestado más atención a asuntos de estructura del discurso que podrían ser útiles para maximizar la calidad de las relaciones entre diferentes enunciados. El chart method - que podría entenderse como una forma bastante sofisticada de control sobre las argumentaciones - se encuentra poco difundido, pese a haberse cumplido ya más de un siglo desde su formulación inicial por WIGMORE (1913), pp. 77-103, y que se cuenta con una interesante literatura que ha ido afinado su uso (ver, por ejemplo, varios trabajos de David Schum y William Twining, entre otros).

${ }^{75}$ En rigor nuestras formas de hablar propenden a que se hable de falsificado para aludir a documentos u objetos y no a discursos.

${ }^{76}$ Así, por ejemplo, el almacenamiento de los recuerdos — una creencia que parece evidente para nuestro sentido común, como también para la ciencia - no habría logrado comprobarse hasta el momento, pese a los esfuerzos por situarla en sectores específicos del cerebro. SHELDRAKE (2013), pp. 247-278

${ }^{77}$ Entre otros, LOFTUS (1996), pp. 88-109.
} 


\section{Polít. Crim. Vol. 15, No 30 (Diciembre 2020), Art. 4, pp. 614-638 [http://politcrim.com/wp-content/uploads/2020/10/Vol15N30A4.pdf]}

falsificado. A lo más constituyen frágiles apoyos para casos que podrían calificarse de patológicos. ${ }^{78}$

Los opuestos de suficiencia e insuficiencia probatoria suponen una aproximación ligeramente distinta a las precedentes respecto a la pretensión de erigir a la verdad por correspondencia como un componente esencial de una teoría de la prueba. Al hablar de suficiencia se introduce un componente relacional, es decir, algo puede ser suficiente en un cierto contexto o momento, pero no en otro. Así las cosas, la suficiencia probatoria ha sido entendida como una variable clave para la aplicación de estándares de prueba, lo que, a la vez, permite lidiar con la incertidumbre cada vez que nos encontremos en un estado que medie entre la demostración o refutación absoluta (suponiendo que algo podemos hacer significar con ello). ${ }^{79}$

Si se analiza el asunto más finamente, el reconocimiento de que los estándares de prueba contribuyen al control de la arbitrariedad, va también de la mano a una renuncia a que el resultado obtenido en un proceso judicial esté determinado por la verdad como correspondencia. ${ }^{80} \mathrm{Si}$ así fuere, tendríamos que estar dispuestos a un lenguaje tan extravagante en el que se acepten afirmaciones tales como: "x era verdad antes, pero ya no en razón de la nueva prueba p"; "z no era verdad hasta antes de la demostración d"; o "z no

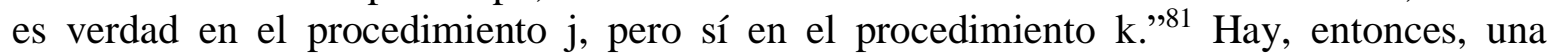
diferencia relevante entre sostener que algo es verdadero y que algo está probado, que va más allá de lo cuantitativo.

El reconocimiento de que la decisión probatoria se encuentra irremisiblemente ligada al tiempo y al espacio en que se decide ${ }^{82}$, incide en la falta de viabilidad de proyectos en que se sostenga en una concepción de progreso fuerte. Debiéramos conformarnos, entonces, con la adaptación a las posibilidades que nos ofrece el entorno. Una teoría de la prueba que ofrezca una perspectiva desde donde operar con pruebas y tomar decisiones, debiera asumirlo. ${ }^{83}$

\section{A modo de cierre}

\footnotetext{
${ }^{78}$ Las condenas por el delito de falso testimonio son muy excepcionales, pese a la habitualidad de declaraciones contradictorias de testigos.

${ }^{79}$ En términos probabilísticos se podrá representar aquello con los guarismos 0 y 1 . Sin embargo, aquello resulta engañoso, ya que lo que reconocemos como demostración o refutación absoluta es más borroso pragmáticamente.

${ }^{80}$ Un punto de vista diferente puede verse en CARNEVALI y CASTILLO (2011), pp. 110-111. La fuente del desacuerdo, sin embargo, podría hallarse en una distinta concepción acerca de lo que implicaría un sistema de enjuiciamiento que asume un compromiso con la verdad por correspondencia. En el planteamiento de estos autores aquella se juega, al menos en el procedimiento penal, en la inexistencia de uno o más votos de absolución suficientemente fundado(s), esto es, que realice(n) un análisis textual minucioso y ceñido a pautas asentadas de racionalidad. Así las cosas, pudiere ser el caso que el desacuerdo sea más aparente que genuino, pues en lo señalado no se advierte un compromiso radical con la realidad, entendida como «lo que está ahí afuera».

${ }^{81}$ RORTY (2000), p. 12.

${ }^{82}$ Hay que estar, entonces, atentos a que en el futuro pudiese generarse o develarse nueva información.

83 AGÜERO (2014), pp. 240-248.
} 


\section{Polít. Crim. Vol. 15, No 30 (Diciembre 2020), Art. 4, pp. 614-638 [http://politcrim.com/wp-content/uploads/2020/10/Vol15N30A4.pdf]}

Pese a los importantes avances tecnológicos — algunos de los cuales han sido asimilados por nuestras prácticas probatorias - no nos encontramos en condiciones de sostener que en asuntos de prueba contamos con el instrumental necesario como para distinguir lo verdadero de lo falso, lo correcto de lo erróneo, lo auténtico de lo falsificado e, incluso, lo suficiente e insuficiente probatoriamente; ello en los términos que exigiría una teoría ambiciosa como lo es la de la verdad como correspondencia. Nuestro estado actual tampoco es de lamentar, pues hay señales de adaptación a las posibilidades que ofrece nuestro entorno.

Para que una teoría resulte exitosa, debiera hacerse cargo de las expectativas y posibilidades de un fino análisis narrativo, tal como podría ocurrir en la historia y otras disciplinas comprometidas con el estudio de las conductas y del lenguaje de los humanos. Los avances - si se decide transitar a través de esta senda - probablemente, no serán espectaculares, pero si suficientemente satisfactorios. Prestar atención a la narrativa no equivale a rendirse a procesos judiciales gobernados por litigantes y jueces con un dominio discursivo que se mantiene impermeable a lo que puedan ofrecerle otras disciplinas. Se trata, más bien, de asumir seriamente lo implicado en la competición de puntos de vista rivales (como ocurre en los alegatos de abogados), y de las decisiones que al respecto se adoptan siguiendo una estructura discursiva que se resiste a ser concebida como un ejercicio puro de poder (como ocurre con las sentencias judiciales). Indagar en las estructuras subyacentes (¿Por qué hablamos o escribimos de la manera en que lo hacemos?) favorece la tarea de optimizar el material probatorio disponible, según se espera de abogados y jueces. ${ }^{84}$ La condición de posibilidad de todo aquello apunta al afinamiento de herramientas de control discursivo sobre las actividades probatorias efectivamente ejecutadas en los procesos judiciales.

En los tiempos que corren, una teoría de la prueba debiera poder asumir lo previamente expresado, lo que, por cierto, no es poco. El problema es que los avances tecnológicos asociados a la construcción de teorías en el campo de la física, química o biología, frecuentemente nos hacen olvidar los límites de los conocimientos (siempre revisables) que estamos en condiciones de producir en los procesos judiciales. En ese orden de cosas, resultan ilustrativas las siguientes palabras de Owen Barfield, expresadas hace algo más de medio siglo:

"Cuando al hombre corriente se le cuenta que la Iglesia dijo a Galileo que podía enseñar el copernicanismo como una hipótesis que salvaba satisfactoriamente todos los fenómenos celestes, pero «no como si fuera la verdad», suele sonreír. ¡Pero era realmente así como se había enseñado la astronomía ptolemaica!... Lo que se temía no era simplemente una nueva teoría sobre los movimientos celestes, sino una nueva teoría sobre la naturaleza de la teoría, a saber: que si una hipótesis salva todas las apariencias, entonces es idéntica a la verdad." 85

Tal vez aún no sean buenos tiempos para las teorías cognoscitivistas en asuntos de prueba y es mejor contentarnos con salvar las apariencias, si con ello podemos aprovechar las posibilidades que al día de hoy se nos ofrecen.

\footnotetext{
${ }^{84}$ BENNETT y FELDMANN (1984), pp. 3 y ss.

${ }^{85}$ BARFIELD (2015), pp. 85-86.
} 
Polít. Crim. Vol. 15, № 30 (Diciembre 2020), Art. 4, pp. 614-638

[http://politcrim.com/wp-content/uploads/2020/10/Vol15N30A4.pdf] 


\section{Polít. Crim. Vol. 15, No 30 (Diciembre 2020), Art. 4, pp. 614-638 \\ [http://politcrim.com/wp-content/uploads/2020/10/Vol15N30A4.pdf]}

\section{Bibliografía citada}

ACCATINO, Daniela (2019): “Teoría de la prueba: ¿somos todos “racionalistas” ahora?”, en: Revus (N³9), pp. 85-102.

AGÜERO, Claudio (2014): "Una crítica al modelo de la narración judicial como explicación científica", en: Ius Et Praxis (Año 20 N$^{\circ} 1$ ), pp. 221-252.

AGÜERO, Claudio (2016): "Los estándares de prueba y el boom editorial del discurso probatorio en castellano", en: Discusiones (N XVIII), pp. 89 -102.

AGUILERA, Edgar. (2016): "Jordi Ferrer y la tradición racionalista de la prueba jurídica: Una mirada crítica” en: Isonomía ( $\left.{ }^{\circ} 44\right)$, pp. 163-189.

ALCHOURRÓN, Carlos y BULYGIN, Eugenio (1991): "Los límites de la lógica y el razonamiento jurídico", en: Análisis lógico y derecho (Madrid, Centro de Estudios Constitucionales), pp.303-328.

ALEXY, Robert. (1989): Teoría de la argumentación jurídica (Madrid, Centro de Estudios Constitucionales).

ANDERSON, Terence; SCHUM, David; TWINING, William (2015): Análisis de la prueba (Madrid, Marcial Pons).

AMAYA, Amalia (2015): "Virtudes y Filosofía del Derecho", en: J.L.F.Z., E. S., Enciclopedia de filosofía y teoría del derecho. (México D.F, UNAM), pp. 17581810

AMAYA, Amalia (2017): "Virtudes y razonamiento probatorio", en: Diálogos jurídicos ( $\left.\mathrm{N}^{\circ} 2\right)$, pp. 19-36.

ARISTÓTELES (2011): Metafísica (Madrid: Gredos Grandes Pensadores).

ARNAU, Juan (2008): Arte de probar. Ironía y lógica en la India antigua (México D. F., Fondo de Cultura Económica).

ARNAU, Juan (2017): La fuga de Dios. Las ciencias y otras narraciones (Girona, Atalanta).

AUERBACH, Erich (1996): Mimesis. La representación de la realidad en la literatura occidental (Buenos Aires, Fondo de Cultura Económica).

BAEHR, Jason (2015): "Cultivating Good Minds: A Philosophical and Practical Guide to Educating for Intellectual Virtues". Disponible en: https://intellectualvirtues.org/why-should-we-educate-for-intellectual-virtues-2-2/ [visitado el 14/11/2019].

BARFIELD, Owen (2015): Salvar las apariencias (Girona: Atalanta).

BAYÓN, Juan Carlos (2008): "Epistemología, moral y prueba de los hechos: hacia un enfoque no benthamiano", en: Analisi e Diritto ( ${ }^{\circ}$ 2008), pp. 15-34.

BENNETT, Lance; FELDMANN, Martha (1984): Reconstructing reality in the courtroom. Justice and Judgment in American Culture (New Brunswick, Rutgers University Press).

BERNS, Sandra (1999): To speak as a judge: difference, voice and power (Aldershot, Ashgate).

BOHM, David (2018): La totalidad y el orden implicado (Barcelona, Kairós).

CHIASSONI, Pierluigi (2011): Técnicas de interpretación jurídica. Breviario para juristas (Madrid, Marcial Pons).

CARNEVALI, Raúl; CASTILLO, Ignacio (2011): "El estándar de convicción de la duda razonable en el proceso penal chileno, en particular la relevancia del voto disidente", en: Ius et Praxis (Año 17, No 2), pp. 77-118. 
COLOMA, Rodrigo; AGÜERO, Claudio (2014): "Fragmentos de un Imaginario Judicial de la Sana Crítica", en: Ius et Praxis (Año 20, N² 2), pp. 375-413.

COLOMA, Rodrigo; AGÜERO, Claudio (2014): "Lógica, ciencia y experiencia en la valoración de la prueba", en: Revista Chilena de Derecho (Año 41, N 2), pp. 673703.

COLOMA, Rodrigo; AGÜERO, Claudio; ACCATINO, Daniela; MARTÍNEZ, Victoria; VARGAS, Valentina (2019): "Pensar la enseñanza del Derecho Probatorio", en: Revista de Derecho de la Pontificia Universidad Católica de Valparaíso (Año 52), pp. 129-152.

COLOMA, Rodrigo (2011): "Las buenas y las malas historias. Criterios de validación del discurso de los hechos en las sentencias judiciales", en: BRUNET, Pierre; ARENA, Federico (dirs.) Cuestiones contemporáneas de teoría analítica del derecho (Madrid, Marcial Pons), pp. 75-97.

COLOMA, Rodrigo (2016): "El Derecho Probatorio y su Torre de Babel: Sobre citas en revistas indexadas", en: Revista de derecho (Valdivia) (Año 29, $\mathrm{N}^{\circ}$ 2), pp. 35-58.

COLOMA, Rodrigo (2019): "La prueba y sus significados", en: Revista Chilena de Derecho (Año 46, Nº 2), pp. 427-449.

COLOMA, Rodrigo (2016): "Los usos de los estándares de prueba: entre umbrales y prototipos", en: Discusiones (XVIII), pp. 23-57.

DE BRASI, Leandro (2020): "Judicial Decisions, Intellectual Virtues and the Division of Labour", en: The International Journal of Evidence and Proof (Volume 24, Issue 2), pp. $142-161$.

DUCE, Mauricio (2015): “Algunas lecciones a partir de cuatro casos de condena de inocentes en Chile", en: Revista de Derecho Universidad Católica del Norte (Año 22, No 1), pp. 149-208.

DUCE, Mauricio (2015): "La condena de inocentes en Chile: una aproximación empírica a partir de los resultados de los recursos de revisión acogidos por la Corte Suprema en el período 2007-2013”, en: Política Criminal (Vol. 10, No 19), pp. 159-191.

ECO, Umberto (1996): Seis paseos por los bosques narrativos. (Barcelona, Lumen).

ECO, Umberto (2018): "Decir falsedades, mentir, falsificar", en: A hombros de gigantes (Madrid, Lumen), pp. 225-256.

ECO, Umberto (2012): "Lo absoluto y lo relativo", en: Construir al enemigo (Barcelona, Lumen), pp. 40-67.

FERNÁNDEZ, José Manuel; OLAVARRÍA, Malva (2018): "Examinando de nuevo la acción de revisión", en: Política Criminal (Vol. 13, № 26), pp. 1190-1285.

FERNÁNDEZ, José Manuel; OLAVARRÍA, Malva (2009): “Teoría y práctica de la acción de revisión en el nuevo código procesal penal, causal letra d) del artículo 473", en: Ius et Praxis (Año 15, $\mathrm{N}^{\circ}$ 2), pp. $215-255$.

GONZÁLEZ LAGIER, Daniel (2020): “¿Es posible formular un estándar de prueba preciso y objetivo? Algunas dudas desde un enfoque argumentativo de la prueba", en Revista telemática de filosofía del derecho $\left(\mathrm{N}^{\circ} 23\right)$, pp. 79-97.

GEERTZ, Clifford (1999): "El sentido común como sistema cultural", en: Conocimiento Local. Ensayos sobre la interpretación de las culturas (Barcelona: Paidós), pp. 93116. 


\section{Polít. Crim. Vol. 15, No 30 (Diciembre 2020), Art. 4, pp. 614-638 [http://politcrim.com/wp-content/uploads/2020/10/Vol15N30A4.pdf]}

HABERMAS, Jürgen (2002): "Racionalidad del entendimiento. Aclaraciones al concepto de racionalidad comunicativa desde la teoría de los actos de habla", en: Verdad y justificación. Ensayos filosóficos (Madrid, Trotta), pp. 99-131.

KAHNEMAN, Daniel (2012): Pensar rápido, pensar despacio (Buenos Aires, Debate).

KUHN, Thomas (1993): "La función de la medición en la física moderna", en: La tensión esencial (Madrid, Fondo de Cultura Económica), pp. 202-247.

KUHN, Thomas (1993): "La tensión esencial: Tradición e innovación en la investigación científica", en: La tensión esencial. (Madrid, Fondo de Cultura Económica), pp. 248262.

LAKATOS, Imre (1983): La metodología de los programas de investigación científica (Madrid, Alianza).

LAUDAN, Larry (2005): "Por qué un estándar de prueba subjetivo y ambiguo no es un estándar”, en: Revista Doxa. Cuadernos de Filosofía del Derecho (Año 28), pp. 95113.

LOFTUS, Elizabeth (1996): Eyewitness testimony (Cambridge, Harvard University Press).

MACCORMICK, Neil (1980): "The coherence of a case and the reasonableness of doubt", en: Liverpool Law Review ( $\left.{ }^{\circ} 2\right)$ Spring-autumm, pp. 45-50.

MAÑALICH, Juan Pablo (2020): "Justicia, procedimiento y acción de revisión. El principio de culpabilidad frente a la cosa juzgada”, en: Ius et Praxis, 26 (1), pp. 28 - 56.

MORIN, Edgar; CIURANA, Emilio; MOTTA, Raúl (2003): Educar en la era planetaria (Barcelona, Gedisa).

NINO, Carlos Santiago (1991): Introducción al Análisis del Derecho (Barcelona, Ariel).

PENNINGTON, Nancy; HASTIE, Reid (2004): "The story model for juror decision making", en: HASTIE, Reid (ed). Inside the juror. The Psychology of Juror Decision Making. (Cambridge, University Press), pp. 192 - 221.

PERELMAN, Chaim (1988): La lógica jurídica y la nueva retórica (Madrid, Civitas).

POPPER, Karl (1989): Conjeturas y refutaciones. El desarrollo del conocimiento científico (Barcelona, Paidós).

POPPER, Karl (2013): “El problema de la demarcación”, en MILLER, David (comp.) Popper: escritos selectos (México, Fondo de Cultura Económica), pp. 131 - 142.

RORTY, Richard (2000): Verdad y progreso (Barcelona, Paidós).

SANDOVAL, Sebastián (2020): "El sentido común y las máximas de la experiencia" (no publicado, citado con permiso del autor).

SHELDRAKE, Rupert (2013): El espejismo de la ciencia (Barcelona, Kairós).

SKOLIMOWSKY, Henryk (2016): La mente participativa (Girona, Atalanta).

TARSKI, Alfred (1960): "La concepción semántica de la verdad y los fundamentos de la semántica", en BUNGE, Mario (ed.) Antología semántica (Buenos Aires, Nueva Visión), pp. 111-157.

TARUFFO, Michele (2007): “Narrativas judiciales”, en: Revista de Derecho (Valdivia) (Año 20, $\left.\mathrm{N}^{\circ} 1\right)$, pp. 231-270.

TODOROV, Tzvetan. (2013): Los usos de la memoria (Santiago, Signos de la Memoria).

TWINING, William (1997): "Pericles and the plumber", en: Law in context: Enlarging a discipline (Oxford, Clarendon Press), pp. 64-88.

TWINING, William (1997): "Taking facts seriously", en: Law in context: Enlarging a discipline (Oxford, Clarendon Press), pp. 89-109. 
TWINING, William (1994): "The Rationalist Tradition of Evidence Scholarship", en: Rethinking Evidence (Evanston, Northwestern University Press), pp. 32-91.

VALENZUELA, Jonatan (2017): Hechos, pena y proceso (Santiago, Rubicón).

WIGMORE, J. H. (1913): "The problem of proof", en: Illinois Law Review (Año 8, º2), pp. 77-103.

WILLIAMS, Bernard (2006): Verdad y veracidad (Barcelona, Tusquets).

WILLIAMS, Bernard (2011): "Conocimiento y razones", en: La filosofía como una disciplina humanística (México D.F., FCE), pp. 66-75. 